\title{
Magnetic Resonance Imaging Brain Size/IQ Relations in Turkish University Students
}

\author{
ÜNER TAN \\ Meliha Tan \\ Karadeniz Technical University, Trabzon, Turkey \\ Pinar Polat \\ Yasar Ceylan \\ Selami Suma \\ ADNAN OKUR \\ Ataturk University, Erzurum, Turkey
}

\begin{abstract}
The relation of IQ (Cattell's Culture Fair Intelligence Test) to brain size was studied in 103 right- and left-handed men and women at Atatürk University in eastern Turkey. Cerebral areas were measured on a midsagittal section of the brain using MRI. An overall correlation of 0.40 was found between MRI-measured total area and IQ thereby further supporting the IQ-brain size hypothesis. Additional analyses suggested that these results may need qualification. In men, only anterior cerebral area correlated with IQ. In women, total and posterior cerebral areas were correlated with IQ. Other results varied by handedness.
\end{abstract}

\section{INTRODUCTION}

Since at least the time of Paul Broca (1824-1880) and Sir Francis Galton (1822-1911) attempts have been made to answer the question whether intelligence can be predicted from brain size. For example, Galton (1888) reported that the head size of Cambridge Class A students was about 3.3\% larger than those of Class B students. Reviews of this literature by Jensen and Sinha (1993), Wickett, Vernon and Lee (1994), Rushton and Ankney (1996) found Galton's results to have been widely replicated.

In Rushton and Ankney's (1996) review, 46 samples were categorized into four sections. From a total of 45,056 children and adolescents, 17 studies found an average correlation of 0.21 (range from 0.08 to 0.35 ) between external head measures and

Direct all correspondence to: Dr. Üner Tan, Department of Physiology, Medical Faculty, Karadeniz Technical University, Trabzon, Turkey. E-mail: unertan@meds.ktu.edu.tr 
estimates of mental ability from ratings, grades, and standardized tests. From 6437 adults, 15 studies found an average correlation of 0.15 (range from 0.02 to 0.39 ) between head-size measures and those of cognitive-ability. From 312 clinical adult patients (e.g., schizophrenics) seven studies found an average correlation of 0.24 (range from 0.07 to 0.38 ) between brain size estimated by CAT and MRI and cognitive ability estimated by educational achievement or by standardized tests. Most importantly, in 381 nonclinical adults, eight studies found an average correlation of 0.44 (range from 0.33 to 0.69 ) between brain size estimated by CAT and MRI and cognitive ability estimated by educational and occupational achievement or by standardized tests.

The eight published studies of in vivo MRI-measured brain size and IQ were all carried out in Western cultures, especially in the United States. Although the head-size/IQ relation has been corroborated in Africans, Amerindians, East Asians, East Indians, and central Europeans, the present investigation is the first one using MRI in a non-Western culture. This study was conducted in eastern Anatolia. We used Cattell's Culture Fair Intelligence test and measured the medial cerebral areas (midsagittal sections) in right- and left-handed young men and women.

Handedness has not yet been considered in studies of the brain-size/IQ relationship. Sex, too, has only rarely been taken into consideration. Because sex and handedness may play an important role in cerebral organization (see Davidson \& Hugdahl, 1995), this study also investigates these issues.

Finally, the question arises as to where "intelligence" is located in the brain. Perhaps surprisingly, in the detailed MRI study by Andreasen et al. (1993) of 67 European American adults ( 37 men, 30 women) with a mean age 38 , most regions of the brain (even including the cerebellum) were equally implicated with few, if any, sex differences. For both sexes, Andreasen et al's highest IQ correlations were with overall brain volume. In the present study, we examine differences between anterior and posterior regions of the brain.

\section{Methods}

\section{Subjects}

Participants were students from the Medical Faculty and the High-School for Sports, Ataturk University, Erzurum. There were 49 men and 54 women, with ages ranging from 18 to 26 years. A narrow age range was preferred in this study, since it is known that brain weight decreases with age (Ho, Roessman, Straumfjord, \& Monroe, 1980; Raz et al., 1997; Peters et al., 1998). Accordingly, Jerison (1979) used subjects older than 27 and younger than 42 years of age in his study concerning correlations between brain size and body height. Our subjects were healthy, devoid of neurological or psychiatric signs and symptoms.

\section{Procedure}

In the first session, participants completed Cattell's Culture Fair Intelligence Test battery (Cattell, 1973) to assess individual differences in fluid intelligence. This is a timed, group administered, multiple choice, pencil-and-paper test. In the present work, Scale 3, Form A for grades 10 to 16 and superior adults was used as a group test (see Tan, 1988). This test is intended to measure intelligence in children and adults in such a way that the influence 


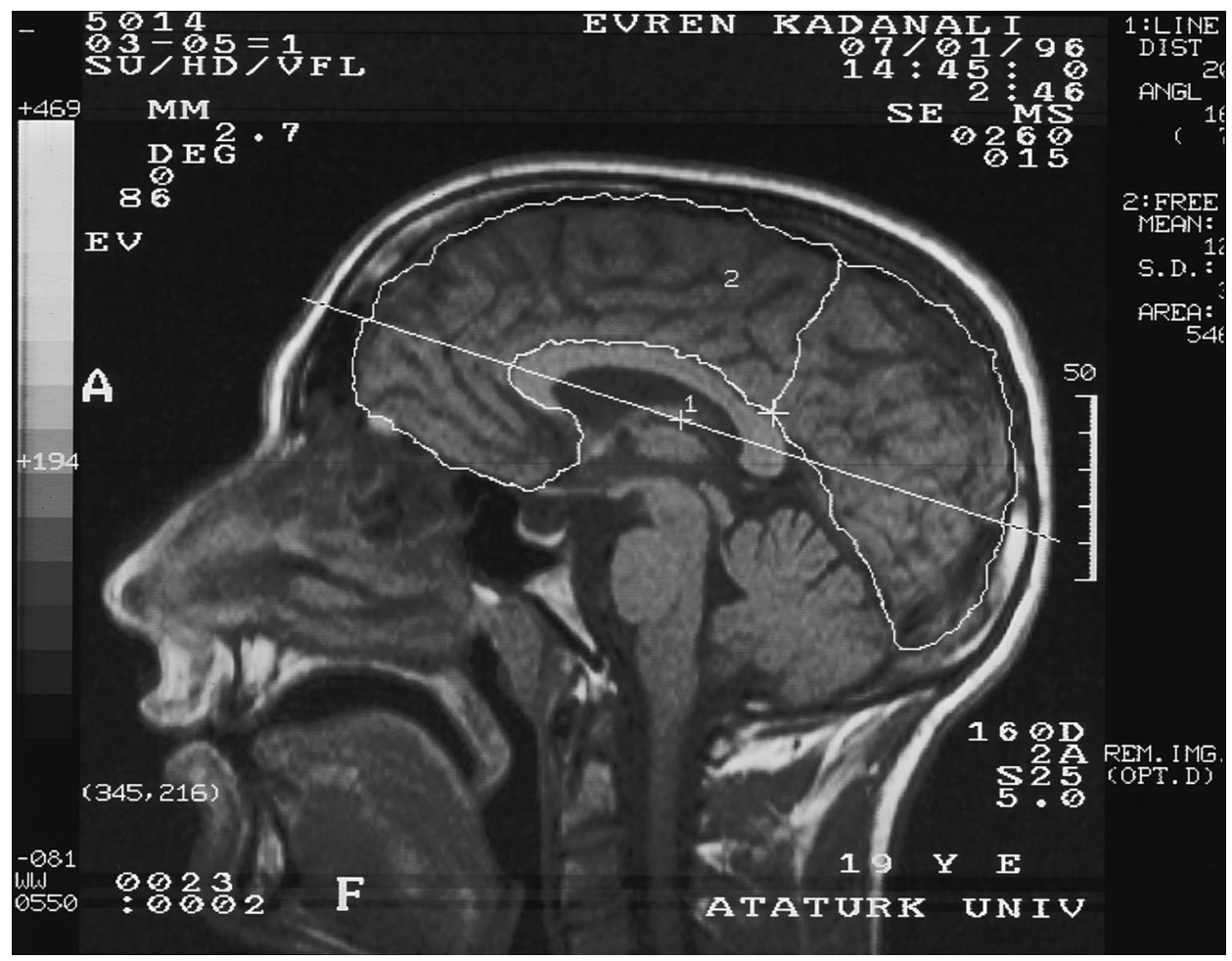

Figure 1. MRI of the midsagittal brain section in a subject. The outer limits of the total cerebral area was drawn by using the cursor (thin line around the cerebrum). The thin line from sulcus centralis separates the anterior and posterior cerebral areas.

of verbal fluency, culture, and educational level have the least effect possible. It focuses mainly on fluid intelligence (the ability to perceive patterns and relationships between things). The items in scale 3 used in the present work are mostly non-verbal and involve series, completion classification, matrix completion, and conditions. Raw scores were converted to normalized scores expressed by age group and scoring was done by using score key overlays with the response forms. Factor analysis shows validity in the 1970 s and 1980s when the general ability (intelligence) factor is correlated with the concepts featured in the subtests (see Cattell, 1987). Our sample had a mean IQ of 108 with a standard deviation of 18 .

In the second session, participants submitted to MRI $(\mathrm{TR}=510$; $\mathrm{TEs}=20$; matrix size $=160 \times 256)$ of the midsagittal plane of the brain. Slices were $10 \mathrm{~mm}$ thick with a gap of $1 \mathrm{~mm}$ using the base of the corpus callosum as the reference point. Scanning was carried out on a $0.5 \mathrm{~T}$ MR equipment. Slices were then stored on an optical disk. At this time, anthropometric head measurements were also taken from the subjects, to the nearest 10th of a millimeter: head length was measured with a spreading calliper from the glabella land mark between the brow ridges to the posterior point on the back of the head. Head breadth was measured with a spreading calliper above the attachment of the ears for maximal 
distance. Head height was measured vertically from the trigone landmark on the cartilaginous flap in front of the ear canal to the horizontal plane tangent to the top of the head.

Hand preference was assessed by the Edinburgh Handedness Inventory (Oldfield, 1971). Those with Geschwind scores (see Tan, 1988) greater than zero with right-hand writing were considered as right-handed; those with Geschwind scores smaller than zero were considered as left-handed. Especially the left-handed subjects were recruited, since they were difficult to find, and this study was not designed to examine the distribution of hand preference.

To determine the cerebral areas, the total cerebrum excluding corpus callosum and pons was hand traced on a computer monitor, and the total cerebral area was computed. The anterior cerebral area was computed after connecting the upper edge of the central sulcus with a reference point at the base of the corpus callosum. The rest was referred as the posterior cerebral area (see Fig. 1). Thus, the medial surface of the midsagittal section of the cerebrum was divided by a line, which began from the central sulcus and ended perpendicular to the corpus callosum. The anterior cerebral area was subtracted from the total cerebral area. In doing so, the size of the posterior cerebral area was obtained. Cranial capacity was calculated from external head measurements using the formula developed by Lee and Pearson (1901), to see whether the measured MRI areas can be used as an index for brain volumes. A correlation analysis was performed to predict the $\mathrm{CC}$ from the midsagittal cerebral areas measured by MRI.

\section{RESUlTS}

Total Samples $(N=103)$

\section{MRI - Measured Cerebral Areas and IQ}

The total cerebral area was found to be highly correlated with IQ for the total sample $(r=0.40, t=4.5, p<0.001)$. Nearly the same correlation was also found for the anterior cerebral area $(r=0.38, t=4.1, p<0.001)$. There was, however, not a significant relationship between IQ and the posterior cerebral area in the same subjects $(r=0.16, t=$ $1.6, p>0.05)$. These results were not largely influenced by the adjustment of the cerebral areas for weight and height.

\section{MRI - Measured Cerebral Areas and Cranial Capacities}

The measured MRI areas were found to be related to cranial capacities evaluated by skull measurements (length, breadth, and height). There were significant correlations between the cerebral areas and cranial capacities for the total samples (total cerebral area: $r=0.72, t=10.6, d f=101, p<0.001$; anterior cerebral area: $r=0.59, t=7.3$, $d f=101, p<0.001$; posterior cerebral area: $r=0.55, t=6.7, d f=101, p<0.001$ ). There were no sex-related differences in these relationships. 
Table 1. The Results of the Correlation Analysis for IQ-MRI Measured Cerebral Areas in Men and Women

\begin{tabular}{|c|c|c|c|c|}
\hline Cerebral Area & $N$ & $r$ & $t$ & $p$ \\
\hline \multicolumn{5}{|c|}{ Total cerebral area } \\
\hline Men & 49 & 0.28 & 1.98 & $=0.05$ \\
\hline Women & 54 & 0.62 & 5.77 & $<0.001$ \\
\hline \multicolumn{5}{|c|}{ Anterior cerebral area } \\
\hline Men & 49 & 0.59 & 4.98 & $<0.001$ \\
\hline Women & 54 & 0.29 & 2.19 & $<0.05$ \\
\hline \multicolumn{5}{|c|}{ Posterior cerebral area } \\
\hline Men & 49 & 0.12 & -0.84 & NS \\
\hline Women & 54 & 0.58 & 5.08 & $<0.001$ \\
\hline
\end{tabular}

\section{Sex-related Differences in IQ-MRI Area Correlations}

Table 1 presents the results of the correlational analysis concerning the relationships of IQ to total cerebral area, anterior cerebral area, and posterior cerebral area for men and women. As seen in Table 1, the total cerebral area correlated with IQ for men, but this correlation was only marginally significant. There was no significant relationship between the posterior cerebral area and IQ for the same subjects. In contrast, all of the cerebral measurements significantly correlated with IQ for women. Only the anterior cerebral area showed a clear-cut correlation with IQ for men.

\section{MRI Cerebral Area-IQ Relationships in Various Handedness Groups}

Table 2 presents the results of the correlational analysis with regard to the relationships of IQ to total cerebral area, anterior cerebral area, and posterior cerebral area for the right- and left-handed men and women. As seen in Table 2, the total cerebral area and the posterior cerebral area were not significantly related to IQ for the right-handed men. For the left-handed men, only the posterior cerebral area was not significantly related to IQ. That is, there was not a significant correlation between the posterior cerebral area and IQ for the right- and left-handed men. Contrarily, only the anterior cerebral area did not show a significant relationship to IQ for the right-handed women. Otherwise, the total cerebral area significantly correlated with IQ for the right-handed women, left-handed women, and only for the left-handed men. There was one exception in IQ-anterior cerebral area correlation: right-handed women. For the posterior cerebral area, the whole male sample, i.e., the right- and left-handed men did not show any significant relationship to IQ.

The total cerebral area was not significantly related to IQ for the right-handed men (see Table 2), but the total cerebral area significantly correlated with IQ for the right-handed women (see Table 2), left-handed men (Table 2), and left-handed women (Table 2).

\section{Sex Differences in Cranial Capacity and MRI-measured Cerebral Areas}

The mean cranial capacity was significantly larger in men than that in women (men: $\mathrm{CC}=1512.4 \pm 95.1 \mathrm{~cm}^{3}$; women: $\mathrm{CC}=1324.6 \pm 76.9 \mathrm{~cm}^{3} ;$ diff. $=187.8 \mathrm{~cm}^{3} ; t=$ 15.6, $d f=204, p<0.001)$. After correcting for height and weight the difference 
Table 2. The Results of the Correlation Analysis for IQ-MRI Measured Cerebral Areas for the Right- (RH) and Left-handed (LH) Men and Women

\begin{tabular}{lllll}
\hline Cerebral Area & $N$ & $r$ & $t$ & \multicolumn{1}{c}{$p$} \\
\hline Total cerebral area & & & & NS \\
$\quad$ RH men & 34 & 0.13 & 0.75 & $<0.05$ \\
RH women & 33 & 0.43 & 2.62 & $<0.01$ \\
LH men & 15 & 0.64 & 3.02 & $<0.001$ \\
LH women & 21 & 0.90 & 8.88 & $<0.001$ \\
Anterior cerebral area & & & & NS \\
RH men & 34 & 0.61 & 4.34 & $<0.005$ \\
RH women & 33 & 0.19 & 1.07 & $<0.001$ \\
LH men & 15 & 0.73 & 3.78 & NS \\
LH women & 21 & 0.75 & 4.88 & $<0.05$ \\
Posterior cerebral area & & & NS \\
RH men & 34 & 0.21 & -1.24 & $<0.001$ \\
RH women & 33 & 0.44 & 2.70 & 0.72 \\
LH men & 15 & 0.19 & 5.69 & \\
LH women & 21 & 0.79 & &
\end{tabular}

between male and female average size was reduced but remained significant (men: cranial capacity $=1463.8 \mathrm{~cm}^{3}$; women: cranial capacity $=1373.1 \mathrm{~cm}^{3}$; diff. $=90.7$ $\left.\mathrm{cm}^{3}, F 3,99=15.8, p<0.001\right)$.

The total cerebral area was significantly larger in men than that in women (mean difference $=671.0 \mathrm{~cm}^{2} ; t=5.2, d f=101, p<0.001$ ). Following adjustment for weight and height, the mean difference between the total cerebral areas did not reach the statistical significance $\left(\right.$ adj. mean for women $=8662.8 \mathrm{~cm}^{2}$, adj. mean for men $=9016.6 \mathrm{~cm}^{2}$; mean difference $\left.=353.8 \mathrm{~cm}^{2}, F 3,99=3.4, p>0.05\right)$.

The anterior and posterior cerebral areas were also found to be significantly larger in men than those in women (anterior cerebral area: mean difference $=353.0$ $\mathrm{cm}^{2}, t=4.37, d f=101, p<0.001$; posterior cerebral area: mean difference $=469.7$ $\left.\mathrm{cm}^{2}, t=5.02, d f=101, p<0.001\right)$. After adjustment for weight and height, the mean anterior cerebral area was not significantly different in men and women (men: adj. mean $=5337.7 \mathrm{~cm}^{2}$; women: adj. mean $=5199.2 \mathrm{~cm}^{2}$; difference $=138.5 \mathrm{~cm}^{2}$; $F 3,99=1.32, p>0.05$ ). There was, however, a significant difference between the posterior cerebral areas of the male and female subjects after adjustment for weight and height (men: adj. mean $=3663.3 \mathrm{~cm}^{2}$; women: adj. mean $=3309.3 \mathrm{~cm}^{2}$; difference $\left.=354 \mathrm{~cm}^{2} ; F 3,99=6.1, p<0.05\right)$.

\section{Relationships Between Cranial Capacity and IQ}

Table 3 presents the correlations between cranial capacity and IQ in the total sample, men, women, and various handedness groups. As seen in this table, IQ significantly correlated with cranial capacity for the total sample, total men, and total women. There was, however, no significant correlation between the cranial capacity and IQ for the right-handed men. Otherwise, the cranial capacity exerted significant correlations with IQ for the right-handed women, and left-handed subjects who showed the highest correlation coefficients. 
Table 3. The Results of the Correlations Between the Cranial Capacity and IQ for the Total Sample, Total Men, Total Women, Various Handedness Groups. RH: Right-handed; LH: Left-handed

\begin{tabular}{lrrrrr}
\hline Subjects & $N$ & $r$ & $t$ & $d f$ & $p$ \\
\hline Total & 103 & 0.25 & 2.64 & 101 & $<0.01$ \\
Men & 49 & 0.29 & 2.10 & 47 & $<0.05$ \\
Women & 54 & 0.55 & 4.80 & 52 & $<.001$ \\
RH men & 34 & 0.17 & 0.96 & 32 & NS \\
RH women & 33 & 0.53 & 3.47 & 31 & $<0.01$ \\
LH men & 15 & 0.70 & 3.50 & 13 & $<.005$ \\
LH women & 21 & 0.59 & 3.20 & 19 & $<.005$ \\
\hline
\end{tabular}

\section{Summary Statistics for the MRI-measured Cerebral Areas}

Table 4 represents the statistical summaries of the cranial capacities and the cerebral areas (total, anterior, and posterior) in the total sample and subsamples (men, women, right- and left-handed subjects).

\section{Discussion}

The results of the present work support the hypothesis that human intelligence is correlated with brain size. Our observed correlation of 0.40 is remarkably close to Rushton and Ankney's (1996) summary of eight previous studies finding an average correlation of 0.44. As such, the brain size/IQ relationship is now confirmed in a non-Western sample. Raz et al. (1993) have also found a similar correlation $(r=0.43)$ between fluid intelligence (Culture Fair Intelligence Test) and MRI-measured brain size, but there were only 29 subjects ranging in age from 18 to 78 years and this correlation dropped substantially after correcting for age.

The mean cranial size calculated for men and women in our sample were a little higher than those normally reported in the international literature (see Rushton \& Ankney, 1997). This may be due to the vagaries of measurement procedures in different studies. This may also be due to the subjects selected from our Faculty of Medicine and High-school for Sports. Accordingly, it was reported that higher occupational status subjects had, on average, larger brains than did lower occupational status subjects (Pearlson et al., 1989; Andreasen et al., 1990; Rushton, 1992; see also Rushton, 1997, pp. 118-125).

Our results concerning the overall sex difference were consistent with those typically reported in the international literature (Ankney, 1992; Rushton \& Ankney, 1997), indicating the converging reliability and validity of all these measures. Namely, we have found that before correcting for height and weight the men averaged $187.8 \mathrm{~cm}^{3}$ $(1.036 \times 187.8=194.6 \mathrm{~g} ;$ see Hofman, 1991) greater capacity than did women; after correcting for the body size variables, this difference was reduced to $90.7 \mathrm{~cm}^{3}(94.0 \mathrm{~g})$. In consistence with these results, Peters et al. (1998) have also found a larger male brain than female brain and this sex difference remained significant in spite of controlling for height. It is interesting, on the other hand, that Pakkenberg and Gundersen (1997) have found that men average four billion more neurons than do women, an enormous $16 \%$ difference. 
Table 4. Statistical Summary of the MRI-measured Cerebral Areas $\left(\mathrm{mm}^{2}\right)$ in the Right- and Left-handed Men and Women. RH: Right-handed; LH: Left-handed; Wom.: Women

\begin{tabular}{|c|c|c|c|c|c|c|c|c|}
\hline \multirow{2}{*}{$\begin{array}{l}\text { Subjects } \\
\text { (N) }\end{array}$} & \multicolumn{2}{|c|}{$C C$} & \multicolumn{2}{|c|}{ Total Area } & \multicolumn{2}{|c|}{ Anterior Area } & \multicolumn{2}{|c|}{ Posterior Area } \\
\hline & Mean & $S D$ & Mean & $S D$ & Mean & $S D$ & Mean & $S D$ \\
\hline Total (103) & 1413.9 & 127.3 & 8823.4 & 730.0 & 5259.9 & 444.6 & 3474.9 & 527.4 \\
\hline Total men (49) & 1512.4 & 95.1 & 9175.2 & 612.7 & 5444.9 & 411.3 & 3721.1 & 552.8 \\
\hline Total wom. (54) & 1324.6 & 76.9 & 8504.2 & 683.6 & 5091.9 & 408.4 & 3251.5 & 389.5 \\
\hline RH men (34) & 1517.7 & 106.0 & 9166.7 & 593.5 & 5453.8 & 377.1 & 3692.2 & 580.1 \\
\hline RH wom. (33) & 1327.8 & 66.3 & 8391.9 & 649.3 & 5175.9 & 422.9 & 3225.5 & 402.1 \\
\hline LH men (15) & 1499.5 & 81.3 & 9194.3 & 675.5 & 5424.8 & 494.2 & 3786.5 & 497.7 \\
\hline LH wom. (21) & 1319.7 & 92.8 & 8680.0 & 714.4 & 4960.0 & 354.8 & 3292.3 & 374.8 \\
\hline
\end{tabular}

The earlier studies that clearly established the brain-size/IQ relation typically did so only after selecting right-handed participants who were (often) of only one sex (Rushton \& Ankney, 1996). Because sex and handedness have often been related to brain organization (Tan, 1990a,b, 1992; Tan, Akgün, \& Telatar, 1993), special attention was paid to sex and handedness of the subjects in the present work. In doing so, we have found that the relation of the total MRI-cerebral area to IQ did not reach the level of statistical significance $(p<0.05)$ for men; the MRI-measured posterior cerebral area did not show a significant correlation with IQ at all, contrary to women. With regard to handedness, the MRI-total cerebral area was not significantly related to IQ for the right-handed men; the MRI-measured posterior cerebral area did not show a significant correlation with IQ for the right- and left-handed men. Although there is no explanation for these results at this time, they imply that the asymmetric brain organization must be taken into account in studies concerning the IQ-brain size relationships.

A detailed analysis showed that there was a significant correlation between the MRI-measured anterior cerebral area and IQ for the right- and left-handed men. Contrarily, there was a significant correlation between the MRI-measured posterior cerebral area and IQ for the right- and left-handed women; the anterior cerebral was not significantly related to IQ for the right-handed women. These results possibly indicate that women use posterior cerebral area and men use anterior cerebral area to process intellectual functions. Accordingly, Bradshaw (1997; pp. 160-161) has suggested that the more professional ideas or specialist processors "expert systems," perhaps subserving aspects of "crystallized" intelligence, may apply more in regions posterior to the sulcus centralis, whereas posterior cerebral structures may be involved in "fluid" intelligence.

In order to answer the question whether the MRI-measured cerebral areas truly reflect the brain size, cranial capacity was calculated using the external skull measures (length, breadth, and height). It was found that all of the MRI-measured cerebral areas (total, anterior, and posterior) significantly correlated with cranial capacity. Thus, the MRImeasured midsagittal cerebral areas can be used as an index for brain volume. In accordance with these results (Finlay \& Darlington, 1995), have reported that the sizes of brain structures correlated closely with absolute brain size.

Additional research using imaging techniques is certain to enrich knowledge of the brain and intelligence. MRI may identify features of the brain that correlate even more 
highly with IQ than does size. Some possibilities are number of neurons, myelination, number of dendrites, white/gray contrast, ventricle/brain ratio, and various brain regions (see Miller, 1994; Rushton \& Ankney, 1996). The numerous interactions possible between sex, handedness, and other variables also need further study.

\section{REFERENCES}

Andreasen, N. C., Ehrhardt, J. C., Swayze, V. W., Alliger, R. J., Yuh, W. T. C., Cohen, G., \& Ziebell, S. (1990). Magnetic resonance imaging of the brain in schizophrenia. Archieves of General Psychiatry, 47, $35-44$.

Andreasen, N. C., Flaum, M., Swayze, V., O’Leary, D. S., Alliger, R., Cohen, G., Ehrhardt, J., \& Yuh, W. T. C. (1993). Intelligence and brain structure in normal individuals. American Journal of Psychiatry, 150, $130-134$.

Ankney, C. D. (1992). Sex differences in relative brain size: The mismeasure of woman, too? Intelligence, 16, $329-336$.

Bradshaw, J. L. (1997). Human evolution. A neuropsychological perspective. East Sussex: Psychology Press, Publishers.

Cattell, R. B. (1973). Manual for the Cattell culture fair intelligence test. Champaign, IL: Institute for Personality and Ability Testing.

Cattell, R. B. (1987). Intelligence: its structure, growth and action. Advances in Psychology. (Vol. 35). Amsterdam, The Netherlands: Elsevier Science.

Davidson, R. J., \& Hugdahl, K. (1995). Brain asymmetry. Cambridge, MA: MIT Press.

Finlay, B. L., \& Darlington, R. B. (1995). Linked regularities in the development and evolution of mammalian brains. Science, $268,1578-1583$.

Galton, F. (1888). Head growth in students at the University of Cambridge. Nature, 38, 14-15.

Ho, K. C., Roessman, U., Straumfjord, J. V., \& Monroe, G. (1980). Analysis of brain weight: I. Adult brain weight in relation to sex, race, and age. Archieves of Pathology and Laboratory Medicine, $104,635-639$.

Hofman, M. A. (1991). The fractal geometry of convoluted brains. Journal für Hirnforschung, 32, 103-111.

Jensen, A. R., \& Sinha, S.N. (1993). Physical correlates of intelligence: A review. In P. A. Vernon (Ed.), The biological basis of intelligence. Norwood: Ablex.

Jerison, H. J. (1979). The evolution of diversity in brain size. In M. E. Hahn, C. Jensen, \& B. C. Dudek (Eds.), Development and evolution in brain size (pp. 29-57). New York: Academic Press.

Lee, A., \& Pearson, K. (1901). Data for the problem of evolution in man: VI. A first study of the Correlation of the human skull. Philosophical Transactions of the Royal Society of London, 196 A, 225-264.

Miller, E. M. (1994). Intelligence and brain myelination: A hypothesis. Personality and Individual Differences, $17,803-832$.

Oldfield, R. C. (1971). The assessment and analysis of handedness: The Edinburgh Inventory. Neuropsychologia, 9, $97-114$.

Pakkenberg, N., \& Gundersen, H. J. G. (1997). Neocortical number in humans: effect of sex and age. Journal of Comparative Neurology, 384, 312-320.

Pearlson, G. D., Kim, W. S., Kubos, K. L., Moberg, P. J., Jayaram, G., Bascom, M. J., Chase, G. A., Goldfinger, A. D., \& Tune, L. E. (1989). Ventricle-brain ratio, computed tomographic density, and brain area in 50 schizophrenics. Archieves of General Psychiatry, 46, 690-697.

Peters, M., Jancke, L., Staiger, J. F., Schlaug, G., Huang, Y., \& Steinmetz, H. (1998). Unsolved problems in comparing brain sizes in Homo sapiens. Brain and Cognition, 37, 254-285.

Raz, N., Torres, I. J., Spencer, W. D., Millman, D., Bertschi, J. C., \& Sarpel, G. (1993). Neuroanatomical correlates of age-sensitive and age-invariant cognitive abilities. An in vivo MRI investigation. Intelligence, 17, 407-422.

Raz, N., Gunning, F. M., Head, D., Dupuis, J. H., McQuain, J., Briggs, S. D., Loken, W. J., Thornton, A. E., \& Acker, J. D. (1997). Selective aging of the human cerebral cortex observed in vivo: differential vulnerability of the prefrontal gray matter. Cerebral Cortex, 7, 268-282.

Rushton, J. P. (1992). Cranial capacity related to sex, rank, and race in a stratified random sample of 6,325 US military personnel. Intelligence, 16, 401-413. 
Rushton, J. P. (1997). Race, evolution, and behavior. New Brunswick (USA) and London (UK): Transaction Publishers.

Rushton, J. P., \& Ankney, C. D. (1996). Brain size and cognitive ability: Correlations with age, sex, social class, and race. Psychonomic Bulletin and Review, 3, 21-36.

Rushton, J. P., \& Ankney, C. D. (1997). Race and sex differences in brain size and cognitive ability. In W. Tomic, J. Kingma (Eds.), Advances in cognition and educational practice (Vol. 4 ) (pp. 25-77). Greenwood, CT: JAI Press.

Tan, U. (1988). The distribution of hand preference in normal men and women. International Journal of Neuroscience, 41, 35-55.

Tan, U. (1990a). Relation of hand skill to spatial reasoning in male and female left-handers with left- and right-hand writing. International Journal of Neuroscience, 53, 121-133.

Tan, U. (1990b). Testosterone and hand performance in right-handed young adults. International Journal of Neuroscience, 54, 267-276.

Tan, U. (1992). Testosterone and estradiol in right-handed men but only estradiol in right-handed women is inversely correlated with the degree of right-hand preference. International Journal of Neuroscience, 66, $25-34$.

Tan, U., Akgün, A., \& Telatar, M. (1993). Relationship among nonverbal intelligence, hand speed and serum testosterone level in left-handed male subjects. International Journal of Neuroscience, 71, 21-28.

Wickett, J. C., Vernon, P. A., \& Lee, D. H. (1994). In vivo brain size, head perimeter, and intelligence in a sample of healthy adult females. Personality and Individual Differences, 16, 831-838. 